\title{
Nociones de trabajo y desocupación en la prensa socialista de fines del siglo XIX
}

\section{Sabina Dimarco}

\author{
Conicet - ICl - UNGS \\ sabinadimarco@hotmail.com
}

Title: Notions of work and unemployment in the socialist press in the late nineteenth century

Resumen: El artículo analiza el modo en que desde el socialismo de finales del siglo XIX se fue conceptualizando al desocupado como categoría y grupo social y el lugar que se le otorgaba en el naciente movimiento obrero. En ese proceso, a su vez, se iba delineando una determinada idea acerca de lo que se esperaba del trabajo. Para ello, analizaremos dos publicaciones de la época: El Obrero (1890-1892) y la primera etapa de La Vanguardia (1894-1900).

Palabras clave: socialismo - clase obrera - desocupación - trabajo

Abstract: The article analyzes the way in which the socialism of the late nineteenth century conceptualized the unemployment as a category and social group, and the way in which, in contrast, a certain idea about how work should it be. To do this, we analyze two publications: El Obrero (1890-1892) and La Vanguardia (1894-1900).

Keywords: socialism - working class - unemployment - work

Recepción: 6 de diciembre de 2018. Aceptación: 15 de enero de 2019 .

(Archivos, año VII, $\mathrm{n}^{\circ}$ 14, marzo de 2019, pp. 97-118) 


\section{Introducción ${ }^{1}$}

La noción de desocupación, entendida como aquella situación de falta transitoria de trabajo por motivos ajenos a la voluntad de quien la padece, empezó a delinearse en los países europeos a finales del siglo XIX y en las primeras décadas del XX. En Argentina, algunos estudios mostraron que la falta de trabajo comenzó a ser objeto de reflexión por parte de expertos ligados a la función pública en el marco de la crisis de 1913 y con más intensidad en la de 1930 (Grondona, 2012; Daniel, 2013; Bertolo, 2008). Sin embargo, la falta de salario como experiencia de vida de los trabajadores antecedió por mucho a esos momentos de problematización, y las organizaciones de izquierda atentas al mundo del trabajo fueron las primeras en abordar la cuestión e intentar nombrar, describir, fundamentar y buscar soluciones para un fenómeno que, entendian, no podía ser pensado bajo las tradicionales conceptualizaciones de la pobreza y la vagancia.

Pobreza y vagancia eran los términos con los que la ausencia (o insuficiencia) de ingresos a través del trabajo había sido tratada a lo largo del siglo XIX. Diversos estudios analizaron el modo en que los pobres válidos que no podían demostrar ocupación ni domicilio fijo eran etiquetados bajo las categorias de vagancia y perseguidos con medidas de carácter represivo mientras que los considerados pobres "merecedores" accedían al aparato asistencial de la Sociedad de Beneficencia. ${ }^{2}$ Desde su creación como brazo asistencial del Estado, esa sociedad se distanció de la tradición colonial de socorro a la pobreza. La lógica de la beneficencia, que suponía mayor sistematicidad en la intervención que la arbitrariedad de la caridad, encontró un sólido punto de apoyo en la demarcación entre pobres merecedores y no -verdaderos y falsos pobres- que formaba parte de las representaciones compartidas en la época (Moreno, 2009; Golbert, 2010). En ese marco, toda pobreza no sustentada en la invalidez era atribuida a la impostura. Ese paradigma recién comenzó a transformarse en parte hacia comienzos del nuevo siglo (González Bernaldo y González Leandri, 2015). ${ }^{3}$

El presente artículo analiza las representaciones de la falta de tra-

1. Agradezco las valiosas sugerencias de los coordinadores del presente dossier. Una versión preliminar de este trabajo fue presentada en las II Jornadas Internacionales de historia del movimiento obrero y la izquierda (2018), organizadas por el CEHTI y la revista Archivos. Agradezco también los estimulantes comentarios de Lucas Poy en aquella oportunidad.

2. Ver los trabajos de Valeria Pita, entre ellos el que se incluye en este dossier.

3. Los autores encuentran en la tesis de 1899 de Luis A. Galli, "De la mendicidad", un testimonio de cambios en la visión de la pobreza. En ella la pobreza (a diferencia 
bajo plasmadas en la prensa socialista en ese momento clave, en lo que refiere a los cambios en las concepciones y el tratamiento de la pobreza en el siglo XIX. En particular, estudia cómo desde el socialismo de la década de 1890 se fue conceptualizando la falta de trabajo como un problema específico y a los desocupados como categoria y grupo social. En ese proceso, veremos, los socialistas se encuentran inexorablemente atravesados por aquellas representaciones hegemónicas que signaron el siglo en que se inscriben, a la vez que las confrontan y proponen concepciones alternativas por momentos más cercanas a las que caracterizarán al siglo venidero.

De este modo, el artículo entabla un diálogo con los trabajos que abordaron la historia de las representaciones de la pobreza en Argentina como asi también con aquellos que indagaron en la historicidad de las categorias sociolaborales ("desocupado" en particular) desde una perspectiva sociohistórica (Topalov, 1994; Zimmermann, 2001). A su vez, se nutre de los estudios sobre la historia de las izquierdas y del movimiento obrero, y fundamentalmente del socialismo en sus primeras etapas y su rol en la estructuración de la clase obrera (Falcón, 1984; Spalding, 1970; Bilsky, 1985; Ratzer, 1969; Poy, 2014; entre otros).

Nuestro corpus se basa en dos publicaciones socialistas de ese período: El Obrero (EO) (1890-1892) y La Vanguardia (LV) en los números correspondientes al período 1894-1900. Ambas comenzaron a publicarse con anterioridad a que el socialismo se constituyese como partido en 1896. Esa "prehistoria" del PS estuvo signada por la publicación de varios periódicos. Como sostuvieron diversos autores, la palabra impresa dirigida a los trabajadores como público específico, en sus múltiples modalidades (periódicos, revistas, folletos, etc.), fue la vía fundamental para la difusión de ideas doctrinarias en todo el arco de las izquierdas (Lobato, 2009; Tarcus, 2007; Camarero y Herrera, 2005). En ese marco se inscribe la aparición de El Obrero. Defensor de los intereses de la clase proletaria, que se posicionó en la filiación del materialismo histórico. A pesar de su corta existencia, este periódico resulta significativo porque fue el órgano de difusión de la incipiente Federación Obrera, pero también porque constituye el primer intento sistemático de interpretación de la realidad argentina en clave marxista (Tarcus, 2007; Martínez Mazzola, 2003-2004). Una realidad, la de la crisis económica y política de 1890, particularmente dificil para quienes vivian de su trabajo. Germán Avé Lallemant, su primer director, ya se había convertido para ese entonces en un referente destacado en el campo intelectual socialista. ${ }^{4}$

de la mendicidad) es definida como un riesgo inherente al trabajo y ya no como la ausencia de disciplina laboral asociada a la "vagancia".

4. Luego de dejar el puesto continuó como colaborador y figura clave del periódico. 
En abril de 1894, a instancias de Juan B. Justo, comenzó a publicarse el que se convertiria en el célebre periódico La Vanguardia. ${ }^{5}$ Como destaca Tarcus, su subtítulo "periódico socialista científico, defensor de la clase trabajadora", resuena como un eco de su antecesor. Y en su primer número rendía homenaje a aquella publicación a la que reconocía como "el primer periódico de la clase obrera argentina" y destacaba a sus principales figuras, Lallemant y Kühn ( $L V, 7$ de abril de 1894), quienes también tuvieron participación en la nueva experiencia editorial. A partir de 1896, con la creación del PS, $L V$ se convirtió en su órgano de difusión oficial.

Es conocido el papel de Justo como traductor de El capital, así como es sabido que a pesar de ser un gran conocedor de la obra de Marx nunca se consideró a sí mismo un "marxista", ni buscó orientar hacia allí al socialismo. Su forma de vincularse con la obra del pensador alemán fue entonces marcadamente diferente a la que entabló Lallemant. De acuerdo con Aricó, se consideraba más bien "un socialista que encontraba en Marx, pero también en otros pensadores, un conjunto de ideas y de propuestas útiles" (1999: 70).

En este escrito las figuras de Lallemant y Justo no nos interesarán en sí mismas sino por la impronta que estos intelectuales del socialismo dejaron en sus publicaciones. Así, más que las personalidades que se encuentran por detrás de las distintas notas que conforman nuestro corpus -a cuyas identidades no siempre nos es posible acceder, por otra parte-, nos interesa cómo estas publicaciones, pensadas como instrumento para el adoctrinamiento y la organización de los trabajadores, fueron forjando una determinada interpretación de la realidad social de su época. En particular, el posicionamiento y la clave interpretativa que adoptaron frente a la cuestión de la falta de trabajo.

Por supuesto, el lugar que ocupó ese tema no puede deslindarse de la situación del mercado de trabajo en el momento histórico concreto en que cada una de esas publicaciones se desarrolló (e incluso, a lo largo de la trayectoria de una misma publicación). Por ello, si bien en el caso de $L V$ analizaremos la totalidad de sus contribuciones desde su aparición y hasta el fin de siglo, nos concentraremos en dos momentos de crisis económicas: la de 1890 (en $E O$ ) y la de 1897 (para $L V$ ).

Este artículo se propone profundizar una línea de indagación que hemos comenzado a desarrollar en otros trabajos (Dimarco, 2016a y 2018a), partiendo de la hipótesis según la cual el socialismo de fines del siglo XIX tuvo un papel relevante en la puesta en forma de una modalidad novedosa de plantear el problema de la ausencia de trabajo.

5. En 1893 se publicaron El Obrero (segunda época) y El Socialista, desprendimientos de $E O$. En ellas no encontramos menciones a este tema. 
En trabajos previos nos concentramos en la crisis de 1890. Nos proponemos aquí analizar el papel que en ese proceso jugaron los socialistas nucleados en torno a La Vanguardia, atendiendo a los cambios que pueden identificarse entre ambos períodos (y periódicos).

Siendo la conceptualización del desocupado nuestro objetivo principal, el artículo indaga en otras dos cuestiones relacionadas. Por un lado, se pregunta por el lugar que este sector de las izquierdas otorgó a quienes empezaban a ser pensados como "desocupados" en su relación con la clase obrera. Por el otro, observa de manera exploratoria el modo en que al problematizar la falta de trabajo iban configurando su reverso: lo que entendian por "trabajo".

\section{El Obrero y los "sin trabajo" en la crisis de 1890}

El Obrero comenzó a publicarse en el contexto de una crisis económica que tuvo fuerte impacto en las posibilidades de generación de empleo y en las condiciones de trabajo y de vida obrera. Durante esos años las principales ciudades, y muy particularmente Buenos Aires, vieron incrementarse la cantidad de personas en busca de alguna ocupación que les permitiese la subsistencia. Ciertamente, los periodos sin ocupación eran frecuentes entre la población trabajadora de la Argentina de mediados del siglo XIX puesto que la ocasionalidad y la inestabilidad caracterizaban al mercado de trabajo de esa estructura productiva agroexportadora ${ }^{6}$ Los desplazamientos entre el empleo rural y urbano, los trabajos ocasionales, la alternancia entre empleo asalariado y por cuenta propia y los periodos sin trabajo eran moneda corriente en ese mercado laboral que se había visto transformado por la llegada masiva de inmigrantes y, con ellos, de una enorme diversidad de oficios, lenguas, ideologias y trayectorias sociales.

Pero a medida que el siglo avanzaba, las posibilidades de trabajo autónomo comenzaron a hacerse más inaccesibles, forzando la proletarización. Hacia 1890, entonces, esos períodos sin ocupación rentada se hacian más dificiles de sobrellevar. Ahora bien, salvo escasísimas excepciones entre las que se encuentran las organizaciones socialistas y anarquistas, esas situaciones de extrema fragilidad en las que las personas se encontraban sin ocupación fueron pensadas en su época -y también por buena parte de la historiografia posterior- como formas de vagancia. Es decir, fueron interpretadas en la clave de una responsabilidad individual. El uso de términos como "vagos" o "atorrantes" en memorias municipales, debates legislativos, actas policiales, prensa

6. Ver los artículos de Pablo Volkind y de Gabriel Di Meglio, Raúl Fradkin y Florencia Thul, en este mismo dossier. 
(no obrera), etc., dan cuenta de esa dificultad para pensar y nombrar situaciones de ausencia de trabajo aún en el marco de una profunda crisis económica.

Es por eso que resulta significativo que, desde sus primeros números, EO haya posicionado la falta de trabajo como un tema de relevancia para el naciente movimiento obrero. Lo hizo desde diferentes frentes: por un lado, disputando decididamente las representaciones hegemónicas relativas a la vagancia y a los atorrantes. Por el otro, enmarcando el problema de la falta de trabajo en la cuestión obrera. Finalmente, promoviendo la organización política de quienes se hallaban en esa situación. Podríamos incluir, aunque de manera menos decidida, los intentos de innovación que buscaban escapar a las categorias habitualmente utilizadas y a las que ellos consideraban claramente estigmatizantes. ${ }^{7}$

En relación al primer punto, dedicaron numerosas notas a contraponer, a lo que consideraban el discurso "burgués" de la vagancia, una representación de los "sin trabajo" que los figuraba como personas voluntariosas, esforzadas, deseosas de encontrar ocupación y dispuestas a cualquier tarea con tal de ganarse por sí mismas el sustento. Con frecuencia, estas notas se planteaban como respuesta a algún artículo publicado en la prensa burguesa, particularmente La Prensa y La Nación. Acusaban a estos medios de construir una imagen distorsionada de la realidad de los "sin trabajo" -como parte de su rol como aparatos de la burguesía- y ridiculizaban las representaciones sobre la vagancia que esa prensa producía.

En cuanto al segundo punto, a través del cuestionamiento a la asociación de la falta de trabajo con la vagancia, y por medio de la movilización de categorías marxistas características del vocabulario de esta publicación, los socialistas de EO reflexionaron sobre los "sin trabajo" en términos de ejército de reserva, es decir, como un sector de la clase obrera transitoriamente sin ocupación pero funcional al capital. En este punto resulta central la forma en que aparecía problematizada la figura del atorrante. Aunque algunas de sus descripciones pueden llevar a pensar en el atorrante como el lumpenproletariado de la categorización marxista (Martínez Mazzola, 2003-2004), lo cierto es que la insistencia con la que lo definían como un "obrero sin trabajo", que quería trabajar pero no encontraba ocupación, se alejaba de aquella noción que Marx reservó a la "escoria" de todas las clases. Para EO los atorrantes constituían "un gran número de trabajadores, que andan en busca de una ocupación" ( $E O, 16$ de enero de 1892). Sostenían incluso que esa figura no era más que una invención burguesa para justificar la represión a las personas que no hallaban dónde ocupar sus fuerzas a cambio de

7. Sintetizamos en este apartado lo trabajado en Dimarco (2016a). 
un salario. No la consideraban, como vemos, una categoria deslindada del mundo obrero y, en este sentido, el atorrante estaba más cercano al ejército de reserva que al lumpenproletariado.

Esto se relaciona con el tercer punto, relativo al plano político-organizativo. Pensarlos en términos de ejército de reserva resultaba importante en el marco de un sector obrero que ellos buscaban forjar como movimiento organizado. Si verlos como lúmpenes deslindados de la clase obrera conducía a desentenderse de su situación, presentarlos como ejército de reserva -en el caso argentino, decian, se trataba fundamentalmente de un "ejército de reserva agricultor" (EO, 27 de junio de 1891)- ubicaba el problema de "los sin trabajo" como un problema obrero, al que debian orientarse también las luchas del socialismo. Así, a comienzos de enero de 1891, desde sus páginas se difundió el primer "meeting de trabajadores sin ocupación" organizado por el Comité Obrero Internacional (EO, 9 de enero de 1891). A ello dedicó una extensa nota que constituye en sí misma una forma de instalar el tema tanto en la agenda gubernamental y mediática como en la de los propios trabajadores.

Mencionamos, como un último elemento a destacar, los intentos por innovar en la forma de nombrar a las personas que se encontraban en una situación de ausencia involuntaria de trabajo de modo de evitar los términos de lo que consideraban una perspectiva burguesa. No sólo buscaban eludir la terminología asociada a la vagancia (mendigos, atorrantes, vagos) sino que se la confrontaba incorporando formas de nominación que incluyeran las palabras "obreros" o "trabajadores". Sin embargo, hay que destacar que en $E O$ no hubo una forma específica de nombrarlos. Se recurrió a una diversidad de fórmulas tales como "obreros sin ocupación", "trabajadores sin trabajo", "trabajadores baldíos", "hombres sin trabajo" o "proletarios sin ocupación". Esto resulta importante porque la inexistencia de un término específico para aludir a ese no-trabajo involuntario da cuenta de la ausencia de una conceptualización estabilizada (Zimmermann, 2001).

\section{La Vanguardia y los "desocupados" entre 1894 y fin de siglo}

\section{La caracterización de la falta de trabajo}

A diferencia de lo ocurrido en torno a la crisis de 1890, poco después, en vísperas del cambio de siglo, comenzó a ser más frecuente que las columnas de la prensa no obrera hiciesen alusión a los "síntomas alarmantes" de la época. Eran los signos visibles de la "cuestión social" (Suriano, 2000). Hacia fin de siglo, efectivamente, el problema obrero 
logró ubicarse, por la fuerza de las movilizaciones, en el centro de las preocupaciones públicas.

Desde los círculos liberal-reformistas la disminución de las posibilidades de empleo solía ser incluida en la serie de problemas que conformaban la "cuestión social" (Zimmermann, 1995). Sin embargo, ello ocurría siempre que el problema fuese pensado como una incertidumbre o dificultad que pudiese afectar a los trabajadores; es decir, como factor de inseguridad de la vida obrera. Pero una vez que la persona se encontraba efectivamente sin ocupación y salía a rebuscárselas para obtener algún magro ingreso, su problemática quedaba inmediatamente excluida de la cuestión obrera para ser percibida y tratada desde la perspectiva de una cuestión de vagancia, en continuidad con la tradición del siglo XIX. Por eso, a pesar de que los problemas obreros estuviesen cada vez más presentes en el ámbito público de esos últimos años del siglo, la percepción respecto de las personas sin trabajo no se había visto sustancialmente modificada (Dimarco, 2016a).

En los años siguientes a su aparición en 1894, La Vanguardia adoptó respecto a este tema una posición algo oscilante para luego, en el marco de la crisis de 1897, inclinarse hacia una postura más cercana a la que había sostenido $E O$. Lo primero que llama la atención al comparar el tratamiento que ambas publicaciones dieron al tema con unos pocos años de diferencia es que en $L V$ se utilizaron con total naturalidad desde el primer momento, en 1894, los términos "desocupación" y "desocupados". Esto es, los movilizaron como si esos términos fuesen de uso corriente. Sin embargo, no sólo prácticamente no se los utilizaba sino que, las pocas veces en que se recurria a esos vocablos, era como sinónimo de mendicidad y vagancia. Por otro lado, no habian sido utilizados ni una sola vez en el $E O$, ni en la principal publicación anarquista de ese mismo periodo, El Perseguido (Dimarco, 2018a).

Si bien $L V$ no desarrolló ninguna definición ni caracterización acerca de dicha categoria, es claro que se la utilizó en un sentido que empezaba a aproximarse a su significado moderno (Topalov, 1994; Pugliese, 2000). Siguiendo a Pugliese, la acepción moderna del término, aunque varía según los países y etapas históricas, presenta al menos tres dimensiones: ausencia de trabajo que genere ingreso, estar en condiciones de trabajar y tener voluntad o disposición para hacerlo. Señala este autor que el criterio de la involuntariedad, es decir el carácter forzoso de la ausencia de trabajo, es uno de los más dificiles de establecer y el más controversial. Es en esa línea, creemos, que los aportes del socialismo a la caracterización de un no-trabajo involuntario resultan más relevantes.

En $L V$, deciamos, se recurrió desde el comienzo y sin definición previa al término desocupados para dar cuenta de personas que no contaban con trabajo pago pero que necesitaban y buscaban trabajar. De 
este modo, se inscribian en un proceso que se estaba dando en países como Alemania, Francia, Inglaterra o Estados Unidos como parte de una configuración reformista, en general proveniente de intelectuales ligados a la función pública. Topalov plantea que los reformadores de esos países debieron inventar (o reformular) un término para inducir distinciones que los usos comunes no hacian (1994: 161). Los términos unemployment/unemployed y chômage/chômeur cumplieron esa función: designaron una figura nueva cuyos contornos se delinearon en la diferenciación con una variedad heterogénea de situaciones de pobreza. El uso del término "desocupados" por parte de los socialistas de $L V$ parece cumplir esa función. Entre la variedad de situaciones que podian conducir a la pobreza, el desocupado era identificado como un obrero involuntariamente sin trabajo. Así, si desde $E O$ se dieron pasos fundamentales en esa conceptualización, con la puesta en marcha de $L V$ se avanzó en la incorporación de un término único y específico para nombrarlo.

Para tomar dimensión de este hecho, vale recordar que el término "desocupado", que es el que llega hasta nuestros días, no fue utilizado por el reformismo liberal sino hasta bastante más tarde. No lo usó Bialet Massé en su célebre informe, ni aparecía mencionado de ese modo en el proyecto de Código de Trabajo de 1904. Gálvez, por su parte, en su importante informe sobre el paro forzoso (1913), planteó que consideraba más apropiado el término "paro forzoso" al de "desocupado", mientras que recurría también a los términos "inocupados" o "chômeur". Recién el informe de Alejandro Unsain de 1920, redactado luego de participar en la Primera Conferencia Internacional de la OIT -hito fundamental en la universalización de una conceptualización del desempleo- puede considerarse un momento importante de estabilización del término (Unsain, 1920; Dimarco, 2018c). Estamos en condiciones de decir, entonces, que la utilización generalizada de los vocablos "desocupación" y "desocupados", en el marco de la publicación socialista, fue un eslabón importante en ese largo proceso de estabilización de un término definido.

Los primeros años de $L V$ transcurrieron en el marco de una mejora de los indicadores económicos que habian signado la grave coyuntura de los años previos. Durante un tiempo, se reactivó la economía y mejoraron los niveles de ocupación dando lugar a un ciclo ascendente de agitación obrera (Poy, 2014). En esa activación de las luchas obreras, la desocupación quedó rezagada en las reivindicaciones frente a otros tópicos relativos a las condiciones del trabajo, tales como la jornada de ocho horas, el trabajo de mujeres y niños, las condiciones del empleo agrícola, entre otros. Pero la falta de trabajo, si bien dejó de tener un peso importante entre las demandas, no estuvo ausente.

Hasta la irrupción de la crisis de 1897, los socialistas consideraban 
que la desocupación no era un problema en Argentina, no obstante lo cual debía prestársele atención. Dado que se lo consideraba un producto natural del capitalismo (y funcional al mismo), el país se dirigía a paso veloz a incorporarse al núcleo de naciones que sufrían ese mal, por lo que no debía ser considerado un problema ajeno. En línea con el socialismo internacional, destacaban el avance del maquinismo como un peligro creciente. Era en la producción agraria y ganadera donde veían el principal riesgo de esos desarrollos, entre los que incluian la incorporación de maquinaria pero también la generalización del alambrado. Ese sector, decían, cada vez "da más empleo a las máquinas y menos a los brazos del hombre". Veían además en la tecnología del alambrado, creada sólo unos pocos años antes (1874) y rápidamente adoptada en el país (Netz, 2004), un problema para la generación de empleo dado que se requería menos personal para cuidar el ganado ( $L V, 5$ de mayo de 1894).

Pero esos señalamientos constituían, en el mejor de los casos, advertencias sobre un futuro no muy lejano más que preocupaciones sobre el presente inmediato. Las consecuencias de la maquinización y el alambrado en la pérdida de fuentes de trabajo habian sido atenuadas, según planteaban, por el avance simultáneo de la superficie cultivada. El peligro radicaba en "tomar ese estado transitorio por definitivo" y creer que "aquí no va a faltar nunca el trabajo" (5 de mayo de 1894). La desocupación ocupó entonces un lugar no desdeñable en los primeros números, pero casi siempre en referencia a otros países como Estados Unidos (7 de julio de 1894; 7 de abril de 1894), Francia (27 de octubre de 1894), Inglaterra y Escocia (31 de agosto de 1895).

La caracterización no difería demasiado de la que se hacía en EO. Se consideraba que era un fenómeno consustancial al capitalismo. Y si bien la noción de ejército de reserva estaba menos presente que en su antecesor, seguía siendo la grilla de lectura desde la que se interpretaba ese "ejército de desocupados". Pero si en EO dicha caracterización conducía a la demanda de intervenciones que redujesen ese excedente, en el caso de $L V$ de esos primeros años se advertía sobre los riesgos de darle al tema el estatus de "problema" y de habilitar así la intervención del Estado.

Esta cuestión aparecía tratada en un artículo traducido del periódico italiano Lotta di classe, sugestivamente titulado "Un problema que no es un problema". Planteaba que liberales y anarquistas coincidian en creer en la "quimera" de que "la sociedad arreglará por sí misma estas anomalías" ( $L V, 5$ de mayo de 1894) y que aunque los liberales consideraban los problemas sociales como fenómenos transitorios el de la desocupación era el que más les preocupaba; "de ahí los innumerables proyectos que deberian, como la piedra filosofal, resolver radicalmente el "problema". Se refería, sin dudas, al trabajo de los reformadores europeos en el 
marco de lo que Topalov (1994) llamó la "invención del desocupado". Los socialistas de Lotta di Classe, en ese artículo que $L V$ se interesó en traducir y difundir, eran por supuesto críticos y desconfiados de esa preocupación burguesa. Pero fundamentalmente consideraban un error "concebir la desocupación como un "problema". Hacerlo, es decir "creer que la desocupación es un fenómeno aislado que puede desaparecer de la sociedad burguesa", suponía, justamente, desconocer por completo la estructura de esa sociedad. En consecuencia, la nota cuestionaba cualquier forma de intervención y desestimaba otorgarle el estatus de "problema" (por lo que recurrian a las comillas para usar el término) puesto que no había resolución posible en el marco del capitalismo.

Desde $L V$ se hacian eco de esa crítica a una intervención sobre el tema-que referían no sólo a la Argentina por la escasa magnitud del fenómeno sino también a Europa-. Esto contrastaba con la batería de propuestas mencionadas (sin desarrollo) en EO: colonias agrícolas y obras públicas (9 de enero de 1891), Bolsa de Trabajo gratuita (21 de febrero de 1891; 29 de agosto de 1891; 20 de febrero de 1892), limitación legal de la jornada de trabajo a ocho horas para distribuir mejor el trabajo disponible (14 de febrero de 1891; 14 de mayo de 1892), y control de la inmigración. Algunas de esas propuestas eran mencionadas en $L V$ con el fin de desestimarlas. En cuanto a las colonias agrícolas, por ejemplo, A. Kühn sostenía que: "[Gracias a ellas] los industriales se surten de obreros, los particulares de sirvientes domésticos, a salarios sumamente bajos, que a su vez influyen infaliblemente en el sentido de bajar los salarios de los demás obreros" ( $L V, 16$ de mayo de 1896).

Hacia mediados de 1896 comenzó a plantearse que el problema había llegado a la Argentina y el tema adquirió un lugar relevante en las páginas del periódico de Justo: "la desocupación forzada es el más cruel tormento para los obreros" ( $L V, 27$ de julio de 1896). A comienzos de 1897 podía leerse que "desde hace años no ha habido tantos obreros sin trabajo como en estos días" ( $L V, 6$ de febrero de 1897). Poco después, Adrián Patroni vaticinaba un duro invierno: "Trabajadores: La crisis avanza, el ejército de desocupados es cada día más numeroso; todo contribuye a demostrar claramente que tendremos un invierno cruel" ( $L V, 10$ de abril de 1897).

En línea con lo sostenido desde $E O$, atribuían las causas a la activa promoción para atraer inmigrantes (lo que llamaban la inmigración "artificial" para contraponerla a la "espontánea"), a lo que se sumaba un año particularmente malo para la agricultura. Según esa nota, "el número abrumador de desocupados [...] presagia muy mal año para la clase trabajadora". A partir de entonces las menciones a este tema fueron cobrando impulso y a mediados de 1897 la Federación Obrera organizó un encuentro de desocupados en el teatro Doria. 
Desocupados, trabajo y clase obrera

A partir de 1890 los socialistas tuvieron un lugar destacado en la organización y estructuración de la clase trabajadora (Falcón, 1984; Bilsky, 1985; Poy, 2014). Ello suponía el desarrollo de una cierta identidad de clase, con sus inclusiones y exclusiones, en un marco de notable heterogeneidad en cuanto a las nacionalidades, diferencias étnicas, idiomáticas, de oficios y de género. En este sentido, resulta significativa la pregunta por la forma en que desde este sector se pensó la articulación entre los excluidos del trabajo y la clase obrera.

De acuerdo a Marx, la población obrera, "con la acumulación de capital producida por ella misma, produce en volumen creciente los medios que permiten convertirla en relativamente supernumeraria" (2004: 785). Esta superpoblación deviene ejército de reserva a disposición del capital para ser reclutado en sus fases expansivas. Ese ejército de reserva funciona como condición de existencia del sistema. Para Marx, entonces, el ejército de reserva no constituía algo distinto de la clase obrera misma. Pero esa no es la única representación de la vida sin salario que se encuentra en su obra. El lumpenproletariado, al que define como la "basura de todas las clases" (1998), compuesta por "vagabundos, delincuentes, prostitutas" (2004: 802), constituye en cambio "una masa bien deslindada del proletariado industrial" (1988: 62). Esta categoria le permite a Marx definir los contornos de la clase obrera, trazando los límites hacia "abajo". Huard (1988) señala que en la obra de Marx el proletariado y el lumpenproletariado van tomando forma de manera paralela y complementaria: mientras que el segundo condensaba los atributos negativos que en su época se atribuian generalizadamente a los trabajadores, el primero pudo erigirse, en contraposición, como una figura liberada de la condena moral. En esa línea, la distinción entre ejército de reserva y lumpenproletariado, a pesar de que en ambos la ausencia de trabajo sea un elemento en común, resulta clave para la estructuración de la clase obrera.

Retomando una pregunta que nos hicimos en relación a $E O$, resulta pertinente interrogarse por el modo en que los "sin trabajo" eran pensados por $L V$ en su relación con la clase obrera. Ya mencionamos que para $E O$ la categoría de atorrante era considerada una invención burguesa destinada a estigmatizar toda forma de no-trabajo y justificar las medidas represivas. Por eso, la figura ocupó un lugar clave en la disputa que entablaron por las representaciones del no-trabajo. En el caso de $L V$, este tema tiene menos lugar, a pesar de que la figura del atorrante seguía estando muy presente en la sociedad de aquella época tal como se refleja en la prensa, el lenguaje de la calle o la narrativa policial, pero también en las obras de importantes referentes intelectuales 
de la época como Ramos Mejía, Miguel Cané o Antonio Dellepiane. No es casual que una de las notas en las que se mencionaba al atorrante proviniese de la pluma de Avé Lallemant. Decía en ella que, en la sociedad argentina de "fin de siécle", "el millonario de la clase high-life, el pequeño burgués de la clase media, el obrero de la clase proletaria y el atorrante de la clase del último residuo social, están allí luchando" ( $L V$, 16 de junio de 1894). El atorrante aparecía claramente por fuera y por debajo de la clase proletaria, como una subclase. En otras ocasiones el término era mencionado de acuerdo al uso generalizado en la época: como sinónimo de vagancia (se hablaba de "vagos y atorrantes"), como atributo descalificativo ("vividores y atorrantes políticos" [los funcionarios], o bien "nos acusan de atorrantes"), o como verbo referido al ocio y la pasividad ("atorrando no nos emanciparemos de la tiranía de los patrones"). Fundamentalmente, se lo mencionaba para dar cuenta de quienes se encontraban en el último estadio de un camino de degradación social. Todo indica, por otra parte, que cuando se recurría a ese término se hacía referencia a la situación de varones jóvenes, en edad de trabajar, mientras que la prostitución aparecía como la situación homóloga para las mujeres.

Fue Adrián Patroni quien desde $L V$ se preguntó por las causas sociales y económicas de su existencia. Decía Patroni que la burguesía preguntaba: “¿Por qué no van a trabajar de peones?”, y agregaba: “Ninguno, o pocos de los que emiten este juicio se encargan de averiguar las verdaderas causas que obligan a muchos hombres a mendigar el pan de cada día" ( $L V, 1$ de mayo de 1895). Si se les preguntaba a los atorrantes sobre su situación, decía, respondian que habian sido obreros: "Yo he sido un obrero, puedo decir más, he sido artista". Luego de un largo desarrollo concluía: "En una palabra, las causas que origina el aumento de los atorrantes es en parte el desarrollo constante de las máquinas, que mediante su perfección dejan cada día mayor número de obreros desocupados". Así, en una línea más cercana a la de $E O$ que a otras menciones encontradas en esta publicación, para Patroni el atorrante era un "obrero desocupado". Con una diferencia sustantiva: para los redactores de $E O$, atorrante era todo obrero sin trabajo víctima de un etiquetamiento estigmatizante por parte de la burguesía y sus aparatos (prensa, policia, etc.); para Patroni, en cambio, la relación entre desocupación y atorrantismo era otra. "Atorrante" no parece ser en este caso una etiqueta que recaía sobre las personas sin trabajo sino que describía un estado efectivo en el que podian caer los "débiles de espíritu". La falta de trabajo podía ser la causa (identificada como causa social) pero eran los factores personales los que explicaban el ingreso a un camino sin retorno: "Es una pendiente -le dijo el atorrante interrogado-: una vez en el fondo, adiós" ( $L V, 1$ de mayo de 1895). De este 
modo, a pesar del intento de desresponsabilización (Patroni aclaraba: "el hombre que llega a ser atorrante jamás ha tenido malos instintos"), y la identificación de causas socioeconómicas, su visión no se alejaba demasiado de la de su época.

La diferencia en el tratamiento de esa figura entre $L V$ y $E O$ resulta relevante en términos de estrategia politica y de estructuración de una identidad obrera. En $L V$, "atorrante" y "desocupado" no constituían una misma figura social, como sí ocurría en $E O$ en donde esa asimilación se constituía en un frente de disputa política. Por el contrario, era en la diferenciación con esas figuras marginales que se iba configurando al desocupado como parte de las luchas obreras:

En un suelto perverso o estúpido se ocupa La Prensa de los "sin trabajo", de los miles de trabajadores desocupados que hay hoy en Buenos Aires y, ni el injusto sufrimiento de estos obreros, ni la importancia y la gravedad de ese fenómeno social, le inspiran otra cosa que insinuaciones malignas y remedios de charlatán. Desde luego se complace en confundir a los trabajadores desocupados con los vagos y rateros de oficio, hablando de unos y otros al mismo tiempo, sin dudas porque unos y otros inspiran a ese diario el mismo interés. ( $L V, 29$ de mayo de 1897)

Era importante no confundir a unos y otros. Una vez deslindada de la capa más marginal del proletariado, la categoría "desocupado" buscaba interpelar de manera amplia a trabajadores de los gremios más variados, pero también a peones y trabajadores por cuenta propia. Planteaban, por ejemplo:

sabemos que no son pocos los trabajadores desocupados: tanto peones, como artesanos y empleados, dificilmente hallan ocupación y la desocupación periódica es lo suficientemente larga para que el malestar de la clase obrera en la Argentina se aproxime cada vez más a la miseria que en Europa acosa a los trabajadores.

De este modo, el problema del desocupado se planteaba como transversal al mundo del trabajo. Pero al mundo del trabajo masculino: la falta de trabajo en las mujeres, a pesar de que podemos suponer que también se había incrementado en esos años, ${ }^{8}$ estaba totalmente ausente

8. La participación femenina en el mercado laboral era para entonces muy significativa. Se desempeñaban tanto en el sector secundario como en el terciario y en trabajos domiciliarios. Ver Falcón (1986), Lobato (2007) y Queirolo (2006). 
en la forma en que era problematizado el tema. Más aún, el trabajo de la mujer aparecía como causa del incremento de la desocupación obrera masculina ( $L V, 31$ de julio de 1897).

Mencionamos ya que a comienzos de 1897 la FOA convocó a una manifestación de desocupados. Los meses previos al encuentro, $L V$ publicó una serie de notas destinadas a mostrar la importancia del tema frente a quienes estaban siendo convocados. La invitación era amplia, "a todos los obreros que se hallen sin trabajo", y se dirigia a los "trabajadores".

Entre las notas que preceden al encuentro, llama la atención una ilustración de considerable tamaño ubicada en la parte superior de la primera página del 26 de junio de 1897. Se titulaba "Desocupados". Era un "grabado de actualidad", suerte de segundo editorial (implementado sólo ese año) que se orientaba a conquistar un público más amplio (Buonuome, 2015). En este caso, apuntaba a la sensibilidad obrera con un cuadro costumbrista que se suponia generalizado en la experiencia de vida de quienes se buscaba interpelar.

La composición consiste en un recuadro dividido en dos partes. De un lado se observa una familia pobre. Un hombre ingresa a una humilde pieza de conventillo en la que se encuentra una mujer con tres niños. Abajo se lee:

Hoy tampoco tienen que hacer fuego -dice el trabajador a su mujer- al entrar a su pieza de conventillo, de vuelta de la larga caminata en que ha ido de taller en taller ofreciendo inútilmente sus brazos. Hace muchas semanas que no encuentra trabajo, y por todo sustento sus hijitos tienen que contentarse con un poco de pan. ( $L V, 26$ de junio de 1897)

Y continúa: "La madre no cocina, los niños apenas comen, el padre vaga lleno de tristeza y de rabia".

Encontramos aquí elementos que estaban presentes en la formulación del problema de los "sin trabajo" en $E O$. Un relato que apelaba a la empatia: un hombre de familia con hijos que mantener, el sufrimiento por no poder garantizar el sustento familiar. En un recurso habitual, la trama se sostenía en la idea de que correspondía al hombre el sostenimiento económico del hogar (Palermo, 2016). La apelación a la idea del varón proveedor otorgaba legitimidad a la demanda de los desocupados. Por esa misma razón, la representación estigmatizante de los "vagos y atorrantes" omitía cualquier referencia a la familia. Y por eso también las mujeres, aunque trabajadoras en un porcentaje considerable, estaban ausentes en la problematización.

A su vez, la imagen recreaba el antagonismo de clase. El grabado "Desocupados" dividia la imagen en dos planos. Del otro lado se encuen- 
tra un matrimonio adinerado en una coqueta habitación. Él también está "desocupado", sin saber en qué usar su improductivo tiempo: "Él se aburre, hastiado de una vida de disipación". Y con esto $L V$ iba al hueso de la concepción moderna del desocupado: el obrero, en cambio, "encontrará mil cosas a qué aplicar con provecho sus fuerzas, pero no le es permitido hacerlo". Lo que faltaba no era la voluntad ni la capacidad de trabajo, sino el trabajo mismo. El desocupado quedaba así claramente posicionado en la clase obrera en oposición a una burguesía parasitaria. La desocupación forzosa del obrero se presentaba como la contracara de la desocupación licenciosa del burgués: “¿por qué no les piden que en lugar de derrochar millones en lujo, y en parrandas por Europa, empleen a los que no tienen trabajo, ocupándose ellos también, los eternos vagos y desocupados, en crear establecimientos de interés general" ( $L V, 6$ de febrero de 1897). Así, el obrero desocupado, parte de la clase obrera, se recortaba en la diferenciación tanto de los "vagos y atorrantes" como del burgués "desocupado".

Pero aún en ese contexto de crisis, se mantiene la tensión en relación a qué estatus otorgarle al tema y a qué debía hacer el Estado, aunque con mayor ambivalencia. Persistía el temor a que la demanda de respuestas ampliara las atribuciones de un Estado en el que no creían; pero sostenian que "un gobierno como el argentino, que gasta sendas sumas en la propaganda por la inmigración, está obligado a evitar que se mueran de hambre los trabajadores que ha hecho inmigrar" (31 de julio de 1897). Así, no sin tensiones, se abria la puerta a las demandas de intervención en un contexto de crisis. Se quejaban, por ejemplo, de que nadie dijese que

en vistas de la escasez de trabajo haya que suprimir los impuestos de consumo, ni que acortar la jornada en los talleres del Estado, ni que emprender mil obras necesarias para el pueblo [...]. Faltan edificios para escuelas, faltan buenos libros para los niños que debieran ir a ellas, falta una buena casa de correos, ¿qué mejor oportunidad para hacerlos?” (LV, 29 de mayo de 1897)

La obra pública aparecía como la vía privilegiada para "paliar momentáneamente la calamidad social de la desocupación", frente a opciones que descartaban como las colonias de desocupados (colonias agricolas) o la caridad. Criticaban a los célebres Talleres Nacionales implementados sin éxito en la Francia revolucionaria, pero proponían obras de saneamiento y embellecimiento a cargo de las municipalidades para dar empleo "a los brazos parados" ( $L V, 31$ de julio de 1897).

De la crítica dirigida a los Talleres Nacionales franceses se desprende 
un último elemento que quisiéramos destacar. El trabajo -decían citando a quien había llevado a cabo una experiencia que consideraban exitosa de obra pública para desocupados en Lancashire (Inglaterra)- debía ser "necesario y útil", pero además "los hombres deben recibir un trato razonable y un pago equitativo" ( $L V, 31$ de julio de 1897). Mientras que los redactores de $E O$ insistian, en pos de demostrar la actitud activa y esforzada, que los "sin trabajo" estaban dispuestos a trabajar "de cualquier cosa", desde $L V$ sostenian que el empleo ofrecido debía cumplir determinadas condiciones. Sin ellas, el desocupado podía rechazarlo sin que se justificara acusarlo de falta de esfuerzo y voluntad. Este punto resulta fundamental porque nos permite ver, a contraluz del problema del desempleo, qué consideraban "trabajo" estos socialistas en ese fin de siglo caracterizado por un mercado de trabajo inestable y marcado por la alternancia entre ocupaciones. A grandes rasgos, esas condiciones eran: salario justo, condiciones laborales dignas, pero también que se respetase el "oficio" en el caso que el demandante de trabajo lo tuviese. Los anuncios de colocación para cortar árboles en Chaco, por ejemplo, eran esgrimidos con insistencia por quienes sostenían que había trabajo para quien lo buscara; frente a eso, desde $L V$ se preguntaban si podía decirse efectivamente que había trabajo disponible cuando el que se ofrecía suponía recorrer extenuantes distancias -con el riesgo incluso de ser detenido bajo las leyes de vagancia-, obligando en muchos casos a abandonar a la familia. O cuando se ofrecian condiciones insalubres y salarios miserables.

Aunque no podamos detenernos en este tema, importa señalar que de este modo se ponía en cuestión uno de los argumentos centrales de la época -y de buena parte de los estudios posteriores- respecto de la existencia de trabajo para todo aquel dispuesto a esforzarse (apelando a los anuncios de colocación en distintas zonas del país y a las frecuentes quejas de los sectores dominantes por falta de mano de obra). Sin entrar en esa controversia directamente (como hacian desde $E O$ ), cambiaban el eje de la discusión: ¿podía considerarse "trabajo" a las ofertas que se mencionaban? ¿O pedirsele a obreros formados en un oficio que dejasen todo para ir a cortar árboles al Chaco o emplearse como lacayos? En este sentido, señalaban con ironía que la nota de $L a$ Prensa ya citada, además de confundir a los "trabajadores desocupados con vagos y rateros de oficio", "por si la humillación no es suficiente agrega que las "familias" de Buenos Aires luchan con dificultades para conseguir buena servidumbre! Ya saben los tipógrafos, pintores, mecánicos, etc. que estén desocupados: pueden, si quieren, entrar de lacayos o mucamos". Y agregaba:

Pero la principal razón que tienen los desocupados, según 
La Prensa, para no quejarse, es que hay en los alrededores de Buenos Aires muchos terrenos fértiles, donde ellos podrian sembrar legumbres. Es decir que sin terreno, sin herramientas, sin semillas, sin instalaciones de riego, sin habitaciones, y $\sin$ competencia especial, los obreros desocupados de la ciudad, en un momento y por un tiempo cualquiera, pueden ir á sembrar legumbres en los alrededores de la Ciudad. ( $L V$, 29 de mayo de 1897)

De este modo, se ponía en cuestión ni más ni menos que la idea de que debía haber disponibilidad absoluta para aceptar cualquier trabajo, en cualquier condición y en cualquier lugar. Punto que resulta de suma relevancia si tenemos presente que la cuestión de la disponibilidad sería un tema central años más tarde para la definición del desempleo por parte de los "expertos".

\section{Reflexiones finales}

Hacia fines del siglo XIX, a pesar de que las crisis económicas tuvieron un considerable impacto en las oportunidades de empleo, las representaciones sobre la pobreza que habian caracterizado a las décadas previas no se vieron sustancialmente modificadas. En ese marco, este artículo tuvo como objetivo analizar el modo en que los socialistas de $E O$ y $L V$ problematizaron ciertas formas de pobreza asociadas a la falta de trabajo como un problema específico, configurando así la figura del "trabajador sin trabajo" o "desocupado".

Ello supuso, en primer lugar, sostener que la falta de trabajo era un problema en Argentina -contra las voces hegemónicas que señalaban insistentemente el problema de la escasez de brazos-. Para EO, que salió a la luz en plena crisis de 1890, no había dudas: coyuntural o no, el tema merecía ser atendido. La disputa por el significado de la figura del atorrante ocupó un papel muy importante en la búsqueda por instalar la falta de trabajo como un problema económico y sistémico, en oposición a la lectura individual y moral.

En $L V$, cuyos primeros números salieron en un momento de cierta recomposición económica, el posicionamiento fue más ambivalente. Esa ambivalencia se matizó, pero se sostuvo, en el marco de la crisis de 1897. No obstante, desde este periódico se dieron pasos fundamentales en la formulación de la noción de "desocupado". Por un lado, se utilizó de manera generalizada ese término para referir a una situación específica de no-trabajo. Pero mientras que desde EO se sostenía, en un posicionamiento casi monolítico, que la idea misma de vagancia (representada de manera paradigmática por la figura del atorrante) era una 
invención burguesa para estigmatizar toda falta de trabajo, y que por tanto los asi llamados eran "obreros sin trabajo" a los que el socialismo debía interpelar, en $L V$ es posible advertir más matices entre quienes escribieron sobre el tema. Por momentos, se observa una visión más cercana a las representaciones que distinguian entre un no-trabajo legítimo y otro moralmente condenable. Menciones a los atorrantes como "el último residuo social" -en la pluma de Ave Lallemant-, o como un estado al que llegaban los "débiles de espíritu" -en Patroni-, ubicaban el componente moral como criterio de demarcación entre el trabajo (en el que se incluían, a diferencia de las representaciones hegemónicas, ciertas formas de no-trabajo legitimas, como la desocupación en trabajadores con oficio) y el no-trabajo condenable ("atorrantes y rateros de oficio" pero también la prostitución como forma de ganarse la vida en las mujeres). Más cerca que $E O$ de la distinción marxista entre ejército de reserva y lumpenproletariado, en $L V$ el desocupado, entendido como ejército de reserva, tomaba forma en la diferenciación con "los vagos y rateros de oficio". Así, en el caso de $L V$ el desocupado emerge en contraposición tanto con el no-trabajo ocioso del burgués como con esas manifestaciones marginales del proletariado identificadas (no sólo por la mirada burguesa sino también por esta publicación) con la vagancia.

Por otro lado, vimos que con la categoría "desocupado" se buscaba interpelar de manera amplia a trabajadores de los gremios más variados, como también a peones y trabajadores por cuenta propia. Se planteaba entonces como transversal al mundo del trabajo masculino. Punto importante en lo que refiere a los intentos por movilizar a este sector.

De este modo, hemos intentado demostrar que estas organizaciones tuvieron un papel destacado en la temprana problematización del desocupado. Buscaron nombrar, describir, fundamentar y proponer respuestas para un fenómeno que, entendían, no podía ser pensado bajo las tradicionales conceptualizaciones de la pobreza y la vagancia. Pero además, en el marco de la conformación de una clase obrera que estaban contribuyendo a estructurar como tal, ubicar ciertas formas de no-trabajo como un problema obrero (distinguiéndolo de un problema de vagancia) tenía un potencial político-organizativo, como se puede ver en los intentos por organizar mítines de "sin trabajo" o "desocupados" tanto en 1890 como en 1897.

Finalmente, mostramos que, a contraluz del problema del desocupado, se iban perfilando las características que debía asumir el trabajo. El cuestionamiento al supuesto de que el obrero desocupado debía tener absoluta disponibilidad para aceptar cualquier trabajo que se ofertase, y la defensa del respeto al oficio, resultan elementos centrales tanto en la definición del desocupado como del trabajo aceptable o digno. Así, si en 1890 el eje de la disputa por el sentido del no-trabajo pasaba en 
gran medida por demostrar que los "sin trabajo" estaban dispuestos a aceptar cualquier empleo con tal de trabajar (como forma de enfatizar la voluntad y disponibilidad), en 1897 desde $L V$ planteaban que bajo ciertas condiciones, el rechazo de un empleo no implicaba falta de voluntad de trabajar. En otros términos, que la existencia de colocaciones en zonas lejanas y por salarios irrisorios no resultaba suficiente para sostener que no había desocupación.

De este modo, $E O$ y $L V$ pusieron en cuestión elementos que habían sido cruciales en las representaciones del no-trabajo a lo largo de todo el siglo XIX y que seguían siéndolo hacia la última década del mismo: la distinción entre buenos y malos pobres, las motivaciones individuales y morales de la ausencia de trabajo, la asociación de todo no-trabajo con la idea de la vagancia y la imagen de la Argentina como un país con oportunidades laborales para todo aquel dispuesto a trabajar. Por otra parte, hay algo de estas ideas movilizadas por el socialismo temprano que nos brinda otras claves para interpretar lo que ha sido caracterizado tantas veces por la historiografia como la "paradoja" de la Argentina de ese momento: la coexistencia de escasez de brazos y abundancia de vagos.

\section{Referencias}

Aricó, José (1999), La hipótesis de Justo: escritos sobre el socialismo en América Latina, Buenos Aires: Sudamericana.

Bertolo, Maricel (2008), Estado y trabajadores en Argentina. El Departamento Nacional del Trabajo ante el fenómeno de la desocupación, 1907-1934, tesis doctoral, Facultad de Filosofia y Letras, UBA.

Bilsky, Edgardo (1985), La FORA y el movimiento obrero/ 1 (1900-1910), Buenos Aires: CEAL.

Buonuome, Juan (2015) "Fisonomía de un semanario socialista: La Vanguardia, 1894-1905", Archivos de historia del movimiento obrero y la izquierda, $\mathrm{n}^{\circ}$ 6, pp. 11-30.

Camarero, Hernán (2015), "El Partido Socialista de la Argentina y sus espinosas relaciones con el movimiento obrero: un análisis del surgimiento y disolución del Comité de Propaganda Gremial, 1914-1917", Izquierdas, $\mathrm{n}^{\circ} 22$, pp. 158-179.

- y Carlos M. Herrera (eds.) (2005), El Partido Socialista en Argentina. Sociedad, politica e ideas a través de un siglo, Buenos Aires: Prometeo.

Daniel, Claudia (2013), "De crisis a crisis: la invención de la desocupación en la Argentina", Revista de Indias, vol. LXXIII, n 257, pp. 193-218.

Dimarco, Sabina (2016a), "Los socialistas y el problema de la falta de ocupación en la crisis de 1890", Estudios Sociales del Estado, vol. 2, n 4.

- (2016b), "Marx y el problema de la falta de ocupación", Astrolabio, n 17. 
- (2018a), "Los "sin trabajo" antes del "desocupado». Socialistas y anarquistas en la construcción de un problema social a fines del siglo XIX", en prensa.

- (2018b), "Atorrantes. Categorias marxistas para una nueva interpretación de una figura popular a fines del siglo XIX en Buenos Aires (El Obrero, 1890-1892)", Izquierdas, no 46, pp. 86-104.

- (2018c), "Argentina, la OIT y el problema del desempleo: procesos de categorización a escala internacional", en Norberto Ferreras, Andrés Stagnaro y Laura Caruso (eds.), A Conexão OIT. América Latina: Problemas regionais do trabalho em perspectiva transnacional, Niteroi: Mauad.

Falcón, Ricardo (1984), Los orígenes del movimiento obrero (1857-1899), Buenos Aires: CEAL.

- (1986), El mundo del trabajo urbano (1890-1914), Buenos Aires: CEAL.

Gálvez, Manuel (1913), La inseguridad de la vida obrera: informe sobre el paro forzoso. Buenos Aires: Imprenta Alsina.

Golbert, Laura (2010), De la Sociedad de Beneficencia a los Derechos Sociales, Buenos Aires: Ministerio de Trabajo y Seguridad Social.

González Bernaldo, Pilar y Ricardo González Leandri (2015), "Regulación pública de la acción social: Beneficencia y educación en el Río de la Plata independiente", Regulación social y regímenes de bienestar en América Latina, Madrid: Polifemo.

Grondona, Ana (2012) "Tradición" y "traducción": un estudio de las formas contemporáneas del gobierno de las poblaciones desempleadas en la Argentina, Buenos Aires: CCC

Huard, Raymond (1988), "Marx et Engels devant la marginalité: la découverte du lumpenproletariat", Romantisme, $\mathrm{n}^{\circ}$ 59, Paris, pp. 5-17.

Lobato, Mirta (2007), Historia de las trabajadoras en Argentina (1869-1960), Buenos Aires: Edhasa

- (2009), La prensa obrera, Buenos Aires: Edhasa.

Martínez Mazzola, Ricardo (2003-2004), "Campeones del proletariado. El periódico El Obrero y los comienzos del socialismo en la Argentina", Politicas de la Memoria, pp. 91-110.

Marx, Karl (1988), Las luchas de clases en Francia (1848-1850), Buenos Aires: Anteo.

- (1998), El dieciocho brumario de Luis Bonaparte, Buenos Aires: Need.

- (2004), El capital, t. 1, vol. 3, Buenos Aires: Siglo XXI.

Moreno, José Luis (2009), Éramos tan pobres...: de la caridad colonial a la Fundación Eva Perón, Buenos Aires: Sudamericana.

Netz, Reviel (2013), Alambre de púas. Una ecología de la modernidad, Buenos Aires: Eudeba.

Oddone, Jacinto (1983), Historia del socialismo argentino, Buenos Aires: CEAL.

Palermo, Silvana (2016), "El derecho a mantener el hogar: demandas obreras en la gran huelga ferroviaria desde una perspectiva de género", en Andrea Andújar et al. (coords.), Vivir con lo justo. Estudios de historia 
social del trabajo en perspectiva de género. Argentina, siglos XIX y XX, Rosario: Prohistoria.

Poy, Lucas (2012), "Socialismo y anarquismo en la formación de la clase obrera en Argentina: problemas historiográficos y apuntes metodológicos”, Archivos de historia del movimiento obrero y la izquierda, $\mathrm{n}^{\circ} 1, \mathrm{pp} .1-34$. - (2014), Los orígenes de la clase obrera argentina. Huelgas, sociedades de resistencia y militancia politica en Buenos Aires, 1880-1896, Buenos Aires: Imago Mundi.

Pugliese, Enrico (2000), "Qué es el desempleo", Politica y Sociedad, n 34, pp. 59-67.

Ratzer, José (1969), El movimiento socialista en la Argentina, Buenos Aires. Spalding, Hall (1970), La clase trabajadora (Documentos para su historia, 1890-1912), Buenos Aires: Galerna.

Suriano, Juan (2000), "Una aproximación a la definición de la "cuestión social" en Argentina" en Juan Suriano (comp.), La cuestión social en Argentina: 1870-1943, Buenos Aires: La Colmena.

Tarcus, Horacio (2007), Marx en la Argentina, Buenos Aires: Siglo XXI.

- (2003), “¿Un marxismo sin sujeto? El naturalista Germán Avé Lallemant y su recepción de Karl Marx en la década de 1890", Politicas de la Memoria, $\mathrm{n}^{\circ}$ 4, pp. 71-90.

Topalov, Christian (1994), Naissance du chômeur, 1880-1910, París: Albin Michel.

Unsain, Alejandro (1920), "Conferencia Internacional del Trabajo", Boletín del Departamento Nacional del Trabajo, n 45.

Walter, Richard (1977), The Socialist Party of Argentina 1890-1930, Texas: University of Texas.

Zimmermann, Bénédicte (2001), La constitution du chômage en Allemagne. Entre professions et territoires, Paris: MSH.

Zimmermann, Eduardo (1995), Los liberales reformistas: la cuestión social en la Argentina, 1890-1916, Buenos Aires: Sudamericana. 